$\xi=$ 不

\title{
Numerical modeling of the tide in the coast area Casablanca-Mohammedia (Morocco)
}

\author{
Laila. Mouakkir*, Soumia.Mordane \\ Polymer Physics and Critical Phenomena Laboratory, Sciences FacultyBen M'sik, P.O Box 7955, \\ University Hassan II, Casablanca Morocco \\ *Corresponding author E-mail: mouakkir_laila@yahoo.fr
}

\begin{abstract}
The objective of this study is to simulate the tidal circulation in the coastal area Casablanca-Mohammedia located on the Moroccan Atlantic. Simulations of the tidal currents of this zone use the 2D version of the MECCA (Model for Estuarine and Coastal Circulation Assessment). These simulations are based on the depth-integrated dynamical equations of turbulent motion. Equations are solved by using the implicit finite-differences techniques. The modelincorporates the actual bottom topography and the effects of the Earth rotation. As forcing mechanism, the model uses the tidal heights prescribed along the open boundaries.
\end{abstract}

As first results, numerical experiments show that the model provides good results compared to those of the altymetric model TPXO.

Keywords: Coast Circulation Modeling; Tide; Finite-Differences; Casablanca-Mohammedia (Morocco).

\section{Introduction}

The majority of water level variability in many coastal regions is tidal in origin, and a distinct advantage in tidal prediction is that tidal responses occur at discrete frequencies determined by combinations of astronomical frequencies as well as frequencies that result from nonlinear interactions in the governing physics. Harmonic analysis of sufficiently long observations of water level have been used historically for accurate local prediction of tides. However, mapping the spatial character of the tides requires accurate tidal models since observational coverage is generally sparse in the deep ocean. In the literature, several models have been developed and applied to coastal areas, in order to simulate hydrodynamic and environmental processes. These models constitute an administrative tool for decision makers in order to apply the right measures to restore the endangered coastal environments.

The purpose of this work is to implement a 2D version the MECCA model applied to the coastal area of the CasablancaMohammedia located on the Moroccan Atlantic. The objective of this modeling is to tempt to produce the major features of the tidal flow in this area. Note that this study is the first one of our laboratory concerning the circulation modeling of CasablancaMohammedia coast.

The present paper is organized as follow: Section 2 starts with a description of MECCA model used for the simulations. It continues showing details on model configuration. The section 3 , describes the study area and the numerical implementation. Section 4 presents the founded numerical results and their discussions, and finally, the conclusions are summarized in section 5 .

\section{Description of the MECCA model}

The two dimensional vertically integrated tidal model MECCA developed by (Smaoui\&Ouahsine 2006) is used for this study. The general circulation model MECCA is initially designed by (Hess 1986) to study costal, estuarine and open ocean circulation. MECCA model is a sigma coordinates, time varying free surface, and primitive equation ocean model. It uses the finite-difference approximations to solve the hydrodynamic equations of momentum, mass, heat, salt and temperature conservation (Hess 2000) on a beta plane, subject to the hydrostatic and Boussinesq approximations.

It is able to simulate time-varying water currents, salinities, and temperatures in shal(1low-water domains at time scales ranging from a few minutes to several months, and space scales stretching from a few kilometers to a few hundred kilometers. The model is designed to simulate circulation driven by tides, wind, and water density gradients as well as atmospheric pressure gradients.

\subsection{Governing equations}

In the orthogonal cartesian coordinate system with horizontal coordinates (x, y) oriented Eastward and northward, respectively, and the vertical coordinate $\mathrm{z}$ increasing upward from the sea surface, the expressions of the linearized equations of motion are: In the $\mathrm{x}$ - direction:

$$
\frac{\partial u}{\partial t}-f v=-\frac{1}{\rho_{0}} \frac{\partial p}{\partial x}+\frac{\partial}{\partial z}\left(A_{v} \frac{\partial u}{\partial z}\right)+F_{u}
$$

In the $\mathrm{y}$-direction:

$$
\frac{\partial v}{\partial t}+f u=-\frac{1}{\rho} \frac{\partial p}{\partial x}+\frac{\partial}{\partial z}\left(A_{v} \frac{\partial v}{\partial z}\right)+F_{v}
$$

And in the $\mathrm{z}$-direction, the hydrostatic balance is 
$\rho g=-\frac{\partial p}{\partial z}$

where $\rho_{0}$ the reference density, $\rho$ the density of sea water, $g$ the gravitational acceleration, $P$ the pressure, Av the vertical eddy viscosity of turbulent momentum, $\mathrm{f}$ is the coriolis parameter, and $\left(F_{u}, F_{v}\right)$ are general forcing terms e.g accounting for lateral mixing.

\subsection{Mixing and diffusion}

In the preceding momentum, temperature and salinity conservation equations, the terms $\mathrm{F}_{\mathrm{u}}, \mathrm{F}_{\mathrm{v}}$, represent turbulent horizontal mixing and diffusion. In the MECCA model, these terms are computed as in the POM model (Blumberg \&Mellor 1987):

$$
\begin{aligned}
& F_{u}=\frac{\partial}{\partial x}\left(2 A_{h} \frac{\partial u}{\partial x}\right)+\frac{\partial}{\partial y}\left[A_{h}\left(\frac{\partial u}{\partial y}+\frac{\partial v}{\partial x}\right)\right] \\
& \mathrm{F}_{\mathrm{v}}=\frac{\partial}{\partial \mathrm{x}}\left(2 \mathrm{~A}_{\mathrm{h}} \frac{\partial \mathrm{v}}{\partial \mathrm{y}}\right)+\frac{\partial}{\partial \mathrm{x}}\left[\mathrm{A}_{\mathrm{h}}\left(\frac{\partial \mathrm{u}}{\partial \mathrm{y}}+\frac{\partial \mathrm{v}}{\partial \mathrm{x}}\right)\right]
\end{aligned}
$$

in which the horizontal turbulent viscosity $A_{h}$ depend on the local velocity shear, deformation rate and the horizontal grid spacing $\Delta$ according to the ( Smagorinsky 1963)formula:

$A_{h}=A_{h 0}+\beta \Delta^{2}\left[2\left(\frac{\partial u}{\partial x}\right)^{2}+2\left(\frac{\partial v}{\partial y}\right)^{2}+\left(\frac{\partial u}{\partial y}+\frac{\partial v}{\partial x}\right)^{2}\right]^{\frac{1}{2}}$

Where $\beta$ is a constant with assigned value of $10^{-2}$ and $A_{h 0}$ is a small background horizontal viscosity of $10 \mathrm{~m}^{2} / \mathrm{s}$.

The instantaneous vertical turbulent viscosity $\mathrm{A}_{\mathrm{v}}$ and diffusion coefficients are calculated using a one-equation turbulence model given in the following text.

The MECCA model was applied successfully to the English Channel area to simulate a tidal flow and the sediment transport (Smaoui 1996). Simulations have shown that the model gives good results concerning the wave propagation (mean velocity, sea elevation) compared to the available data or other existing models. However, simulations of the dispersion of the fresh water plume show some difference between the available observations (Smaoui 1996): MECCA overestimates the width of the fresh water plume. This difference has been attributed to the turbulence-closure scheme initially used in the model (zero-equation model), and to the implicit mixing caused by the spatial discretization of the advective term. To solve in part this problem, we have introduced a one-equation model that consists in solving an equation for the turbulent kinetic energy, $\mathrm{K}$, and a semi-empirical expression for the mixing length. The selection of this turbulent scheme is justified by (i) the shallow depth in the simulated region, which makes the boundary layer thickness occupy nearly the totality of the water column and (ii) our modest means of computation.

This kind of turbulence parameterization is formulated as follows:

$\frac{\partial \mathrm{K}}{\partial \mathrm{t}}-\stackrel{\nabla}{\sigma} \nabla \mathrm{K}=\frac{\partial}{\partial \mathrm{z}}\left(\frac{\mathrm{A}_{\mathrm{V}}}{\partial \mathrm{K}} \frac{\partial \mathrm{K}}{\partial \mathrm{z}}\right)+\mathrm{P}+\mathrm{G}+\mathrm{D}_{\mathrm{K}}-\varepsilon$

Where $\mathrm{P}$ is the shear production of turbulent kinetic energy, $\mathrm{G}$ is the rate of conversion of turbulent kinetic energy into potential energy which appears as the dissipation of turbulent kinetic energy by buoyancy, $D_{k}$ is the horizontal diffusion of turbulent kinetic energy and $\varepsilon$ is the turbulent energy dissipation rate

The general expression for the mixing length $\ell$ is a function of the turbulent kinetic energy and depends on the mixing lengths $\ell_{0}$ and $\ell_{\mathrm{m}}$ (Blackadar 1962), where the mixing lengths $\ell_{0}$ and $\ell \mathrm{m}$ are given by:

$$
l_{0}=\frac{\kappa z}{1+\kappa z / l_{m}}
$$

And

$$
1_{\mathrm{m}}=\gamma_{0} \frac{\int_{\text {bed }}^{\text {surface }} \mathrm{z} \sqrt{\mathrm{K}} \mathrm{dz}}{\int_{\text {bed }}^{\text {surface } \sqrt{\mathrm{K}} \mathrm{dz}}}
$$

In which $\kappa=0.4$ is the Von Kàrman constant and $\gamma_{0}$ is a constant in the range 0.1 to 0.4 .

In stratified flow configurations, the MECCA model uses the corrected mixing length $\ell$ proposed by (Munk\& Anderson 1948):

$$
l=l_{0}[1+10 R i]^{-0.5}
$$

Where $\mathrm{R}_{\mathrm{i}}$ denotes the Richardson number defined as:

$$
\mathrm{R}_{\mathrm{i}}=-\frac{\mathrm{g}}{\rho} \frac{\partial \rho}{\partial \mathrm{z}}\left[\left(\frac{\partial \mathrm{u}}{\partial \mathrm{z}}\right)^{2}+\left(\frac{\partial \mathrm{v}}{\partial \mathrm{z}}\right)\right]^{-1}
$$

The eddy viscosity $A_{v}$ and are computed as functions of the turbulent kinetic energy and the mixing length according to:

$$
A_{v}=C_{\mu} K^{1.5} l
$$

Where $\sigma_{s}$ is the Prandtl number.

\subsection{Numerical solution}

Numerical solution of the set of equations of model uses a well known techniques called «mode separation: the external and internal modes». The external mode computes the sea surface elevation $(\eta)$ and the mean velocity $(u, v)$ by solving a set of vertically integrated equations of continuity and motion. The internal mode solves the vertical contribution of the velocity during the motion defined as the departures from the mean velocity.

The foundation of the numerical solution is the calculation of the external mode velocity $(u, v)$ and the sea surface elevation $(\eta)$. The computation technique is similar to those classical verticallyintegrated models. MECCA employs an alternating-directions implicit method to compute $\mathrm{u}$ and an approximation of non the first sweep, then $\mathrm{v}$ and $\eta$ on the second sweep. The application is relatively straight forward, but with non-linear advective terms approximated with upstream differencing and the bottom stress partitioned into internal and external mode components.

\section{Application of MECCA model}

\subsection{Model grid and topography}

The region concerned by the simulation includes the site of Casablanca-Mohammadia located at the west of Morocco on the Atlantic coastline North (figure 1). The examination of the CasablancaMohammedia batymetric map shows a regular slop from the coast to $-30 \mathrm{~m}$. In this zone, we note the presence of three very marked capes, to which are associated submarine ridges. The capes en question are: cape Dar Bouazza $\mathrm{C} 1$, cape Elhank c2, and cape Fedala C3.

The model zone extends longitudinally from $7^{\circ} 2^{\prime}$ to $8^{\circ}$, and at latitude from $33^{\circ} 45^{\prime}$ to $34^{\circ}$. The bathymetry data is a combination of ETOPO5 in deep water, and NOAA's, Coastal Relief Modelavailable at (http://www.ngdc.noaa.gov/mgg/global/global.html) (figure (1)).After interpolation of these data, we obtained in the horizontal plane a regular grid of $1 \mathrm{~km} \times 1 \mathrm{~km}$, resulting in a hori- 
zontal configuration with74 points in the x-direction, and 61 points in the y-direction.

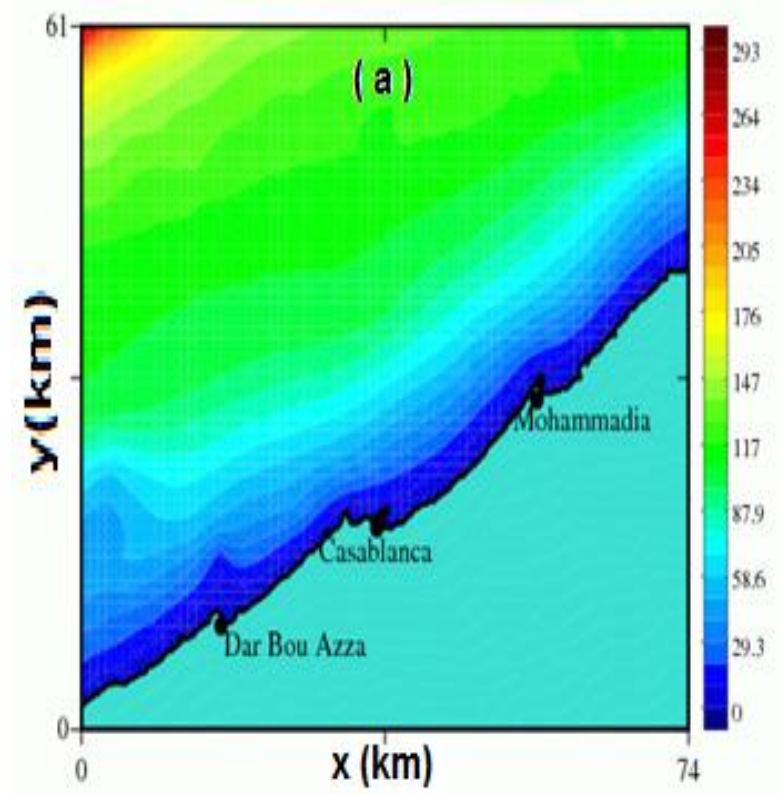

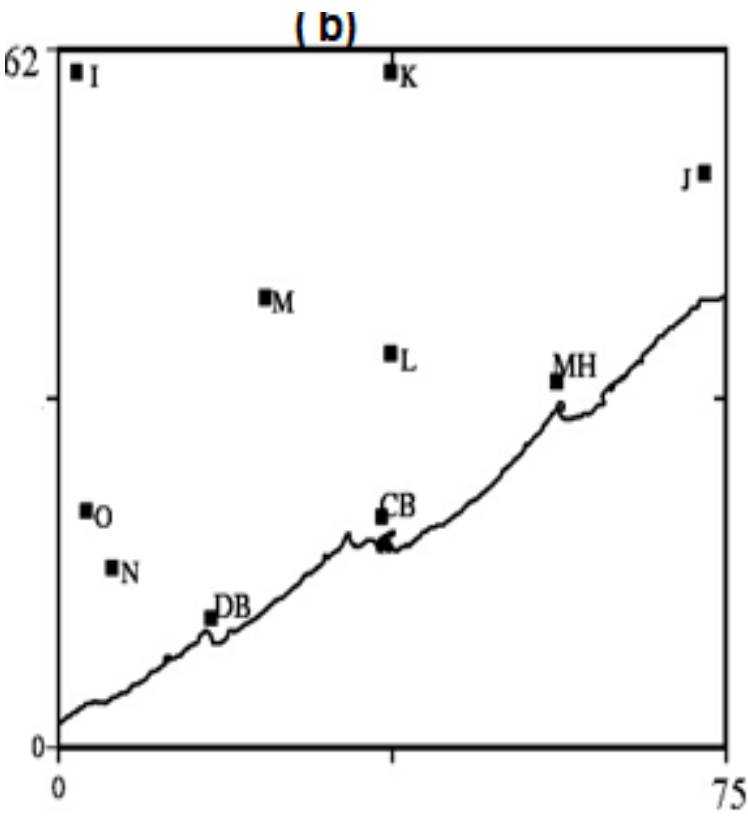

Fig. 1: (a) Bathymetry of the Casablanca-Mohammedia Coast. (b) Localization of Points Output of Results.

\subsection{Boundary conditions}

The discretization of the external mode equations requires knowledge limtes to open either the slope of the free surface or components average speed $(\overline{\mathrm{u}}, \overline{\mathrm{v}})$. In our case and in order to minimize the harmful effects due to the wave reflection at the boundaries, a forced Orlanski radiation condition is used at both boundaries for the sea surface elevation in the same way of (Bills \&Noye 1987). This kind of boundary conditions needs a value of the sea elevation at the grid points located on the open boundary. The modeling takes into account the main five tidal components (M2, $\mathrm{S} 2, \mathrm{~N} 2, \mathrm{~K} 1$, and O1).Finally the tidal signal at the open boundaries of the domain will be written as:

$$
\eta(y, t)=\sum_{n=1}^{2} a_{n}(y) \cos \left(\sigma_{n} t-\varphi_{n}(y)\right)
$$

Wherean $(y)$ and $\varphi_{n}(y)$ are respectively, the amplitude and the phase of the harmonic of the tidal signal and $\sigma_{\mathrm{n}}$ is its frequency. As noted above these values are extracted from the database and the digital elevation model derived from TPXO 7.1 global model of ocean tides model (Cherniawsky, et al 2001). On then does a linear interpolation to estimate in each point of mesh along the open boundary.

\section{Results and discussion}

A comparison (tables 1, 2, 3, 4, 5) between the numerical results of the MECCA and TPXOhas been conducted. Also in these tables we add the simulated amplitudes and phases of the fivemain tidal constituents(M2, S2, N2, K1, O1) in the points located on the whole study zone(offshore and closer to the coast).One can observe a good agreement between the results of the MECCA model and those of the TPXO model. In order to quantify the errors in amplitude and in phase, the mean range between values simulated by MECCA model and values calculated by TPXO model, has been determined and is given in Table 6according to the considered tidal wave. In terms of amplitude, the difference between MECCA and TPXO model are small for the M2, S2 tidal waves. We observe a weak overestimation of the amplitudes of the $\mathrm{K} 1$ wave calculated by TPXO (of the order of $2.7 \mathrm{~cm}$ ) compared with the values of MECCA model.
Table 1: Comparison of the Amplitude and the Phase of the M2 Wave Calculated by the Models MECCA and TPX0 at Several Points in the Coastal Zone Casablanca-Mohammedia Area

\begin{tabular}{lllll}
\hline Points & $\begin{array}{l}\text { Model MECCA } \\
\text { Amplitude } \\
(\mathrm{m})\end{array}$ & Phase $\left(^{\circ}\right)$ & $\begin{array}{l}\text { Model TPXO } \\
\text { Amplitude } \\
(\mathrm{m})\end{array}$ & Phase $\left(^{\circ}\right)$ \\
\hline $\mathrm{CB}$ & 1.005 & 52.85 & 0.999 & 53.20 \\
$\mathrm{MH}$ & 1.005 & 53.16 & 1.001 & 53.20 \\
$\mathrm{I}$ & 0.988 & 52.87 & 0.988 & 53.00 \\
$\mathrm{~J}$ & 1.000 & 53.31 & 0.998 & 53.50 \\
$\mathrm{~K}$ & 0.995 & 53.01 & 0.994 & 53.09 \\
$\mathrm{~L}$ & 1.002 & 52.98 & 0.999 & 53.00 \\
$\mathrm{M}$ & 0.997 & 52.86 & 0.995 & 52.90 \\
$\mathrm{~N}$ & 0.998 & 52.55 & 0.995 & 52.60 \\
$\mathrm{O}$ & 0.996 & 52.57 & 0.995 & 52.60 \\
\hline
\end{tabular}

Table 2: Comparison of the Amplitude and the Phase of the S2 Wave Calculated by the Models MECCA and TPX0 at Several Points in the Coastal Zone Casablanca-Mohammedia Area

\begin{tabular}{|c|c|c|c|c|}
\hline \multirow[b]{2}{*}{ Points } & \multicolumn{2}{|c|}{ Model MECCA } & \multicolumn{2}{|c|}{ Model TPXO } \\
\hline & $\begin{array}{l}\text { Amplitude } \\
\text { (m) }\end{array}$ & Phase $\left({ }^{\circ}\right)$ & $\begin{array}{l}\text { Amplitude } \\
\text { (m) }\end{array}$ & Phase $\left({ }^{\circ}\right)$ \\
\hline $\mathrm{CB}$ & 0.357 & 78.40 & 0.362 & 78.40 \\
\hline MH & 0.357 & 78.32 & 0.363 & 78.70 \\
\hline I & 0.354 & 78.62 & 0.358 & 78.40 \\
\hline $\mathrm{J}$ & 0.354 & 78.87 & 0.362 & 79.00 \\
\hline $\mathrm{K}$ & 0.355 & 78.33 & 0.360 & 78.70 \\
\hline $\mathrm{L}$ & 0.356 & 78.34 & 0.361 & 78.50 \\
\hline M & 0.355 & 78.54 & 0.360 & 78.40 \\
\hline $\mathrm{N}$ & 0.355 & 78.86 & 0.360 & 78.10 \\
\hline $\mathrm{O}$ & 0.354 & 78.87 & 0.360 & 78.10 \\
\hline
\end{tabular}

Table 3: Comparison of the Amplitude and the Phase of the N2 Wave Calculated by the Models MECCA and TPX0 at Several Points in the Coastal Zone Casablanca-Mohammedia Area

\begin{tabular}{|c|c|c|c|c|}
\hline \multirow[t]{2}{*}{ Points } & \multicolumn{2}{|c|}{ Model MECCA } & \multicolumn{2}{|c|}{ Model TPXO } \\
\hline & $\begin{array}{l}\text { Amplitude } \\
\text { (m) }\end{array}$ & Phase $\left({ }^{\circ}\right)$ & $\begin{array}{l}\text { Amplitude } \\
\text { (m) }\end{array}$ & Phase $\left(^{\circ}\right)$ \\
\hline $\mathrm{CB}$ & 0.209 & 36.8 & 0.216 & 36.40 \\
\hline MH & 0.209 & 36.7 & 0.216 & 37.10 \\
\hline I & 0.206 & 36.88 & 0.213 & 36.48 \\
\hline $\mathrm{J}$ & 0.210 & 36.41 & 0.215 & 36.80 \\
\hline K & 0.208 & 36.7 & 0.214 & 36.90 \\
\hline $\mathrm{L}$ & 0.208 & 36.84 & 0.215 & 36.5 \\
\hline M & 0.208 & 37.11 & 0.214 & 36.4 \\
\hline $\mathrm{N}$ & 0.208 & 36.84 & 0.214 & 36.2 \\
\hline 0 & 0.207 & 37.12 & 0.213 & 36.50 \\
\hline
\end{tabular}


Table 4: Comparison of the Amplitude and the Phase of the K1 Wave Calculated by the Models MECCA and TPX0 at Several Points in the Coastal Zone Casablanca-Mohammedia Area

\begin{tabular}{|c|c|c|c|c|}
\hline \multirow[t]{2}{*}{ Points } & \multicolumn{2}{|c|}{ Model MECCA } & \multicolumn{2}{|c|}{ Model TPXO } \\
\hline & $\begin{array}{l}\text { Amplitude } \\
\text { (m) }\end{array}$ & Phase $\left(^{\circ}\right)$ & $\begin{array}{l}\text { Amplitude } \\
\text { (m) }\end{array}$ & Phase $\left(^{\circ}\right)$ \\
\hline $\mathrm{CB}$ & 0.045 & 50.60 & 0.068 & 50.3 \\
\hline MH & 0.045 & 50.62 & 0.068 & 50.4 \\
\hline I & 0.045 & 50.28 & 0.068 & 50.6 \\
\hline $\mathbf{J}$ & 0.045 & 50.50 & 0.068 & 50.4 \\
\hline $\mathrm{K}$ & 0.045 & 50.56 & 0.068 & 50.5 \\
\hline $\mathrm{L}$ & 0.045 & 50.60 & 0.068 & 50.4 \\
\hline M & 0.045 & 50.48 & 0.068 & 50.4 \\
\hline $\mathrm{N}$ & 0.045 & 50.48 & 0.068 & 50.4 \\
\hline 0 & 0.045 & 50.37 & 0.068 & 50.3 \\
\hline
\end{tabular}

Table 5: Comparison of the Amplitude and the Phase of the O1 Wave Calculated by the Models MECCA and TPX0 at Several Points in the Coastal Zone Casablanca-Mohammedia Area

\begin{tabular}{|c|c|c|c|c|}
\hline \multirow[t]{2}{*}{ Points } & \multicolumn{2}{|l|}{ Model MECCA } & \multicolumn{2}{|l|}{ Model TPXO } \\
\hline & Amplitude (m) & Phase $\left({ }^{\circ}\right)$ & Amplitude (m) & Phase $\left(^{\circ}\right)$ \\
\hline $\mathrm{CB}$ & 0.032 & 308.44 & 0.059 & 308.1 \\
\hline MH & 0.032 & 308.40 & 0.059 & 308.2 \\
\hline I & 0.032 & 307.86 & 0.059 & 308.0 \\
\hline J & 0.032 & 307.50 & 0.059 & 308.3 \\
\hline K & 0.032 & 307.54 & 0.059 & 308.2 \\
\hline $\mathrm{L}$ & 0.032 & 308.38 & 0.059 & 308.0 \\
\hline M & 0.032 & 308.36 & 0.059 & 308.0 \\
\hline $\mathrm{N}$ & 0.032 & 308.00 & 0.059 & 307.7 \\
\hline 0 & 0.032 & 308.31 & 0.059 & 307.4 \\
\hline
\end{tabular}

Table 6: Average Difference between the MECCA and TPXO Models for the Tidal Waves M2, S2, N2, K1, and O1

\begin{tabular}{lll} 
Wave & $\begin{array}{l}\text { Average Difference in } \\
\text { amplitude }(\mathrm{cm})\end{array}$ & $\begin{array}{l}\text { Average Difference in } \\
\text { phase }\left(^{\circ}\right)\end{array}$ \\
\hline M2 & 0.24 & 0.075 \\
S2 & 0.56 & 0.16 \\
N2 & 2.05 & 0.11 \\
K1 & 2.7 & 0.035 \\
O1 & 2.3 & 0.944 \\
\hline
\end{tabular}

Figure (2) show the sea surface elevation during 40 days for the Mohammedia, and Casablanca. This station is close to the coast, the spring-neap cycle is pronounced and one can observe the amplitude difference of sea surface elevation during two consecutive high waters due to the two diurnal tidal waves used in this simulation.

The sea surface elevation field and the currents field at low and high water are presented in figures (3) and (4) respectively. The mean vertically integrated currents (figure. 3) are essentially directedto the coast at high tide.At low tide, the tidal currents change direction; they are oriented towards the sea (figure 4).

Figure (5) show the residual velocity, we have studied the residual transport induced by the maintidal constituent, i.e. the M2 wave, to model the Casablanca-Mohammedia circulation. The residual transport is expressed as the temporal mean of transport by including an integer of the studied M2 wave period. From this figure, we note that the residual flows are maximum at Neighborhood of the three headlands of the area (Dar Bouazza, Al hank and Feddala (Mohammedia)), in the direction of the flow with a direction South-South-West. Offshore, the residual flows are very weak and do not a net directional.

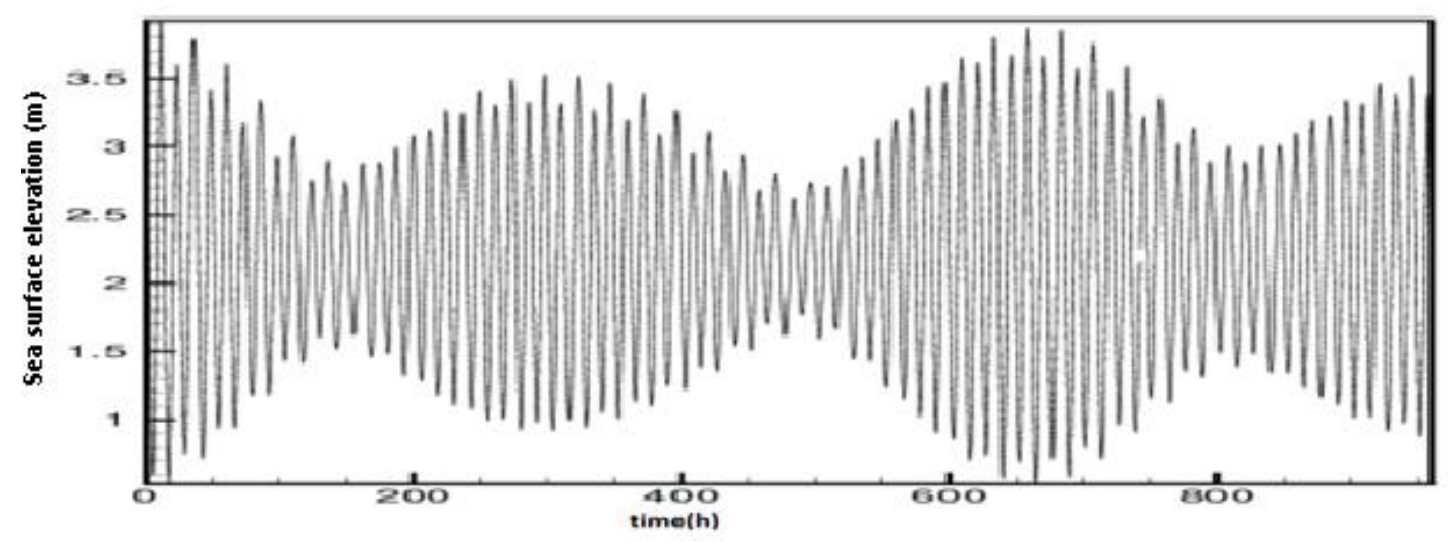

Fig. 2: Time Evolution of the Sea Surface Elevation at Mohammedia.

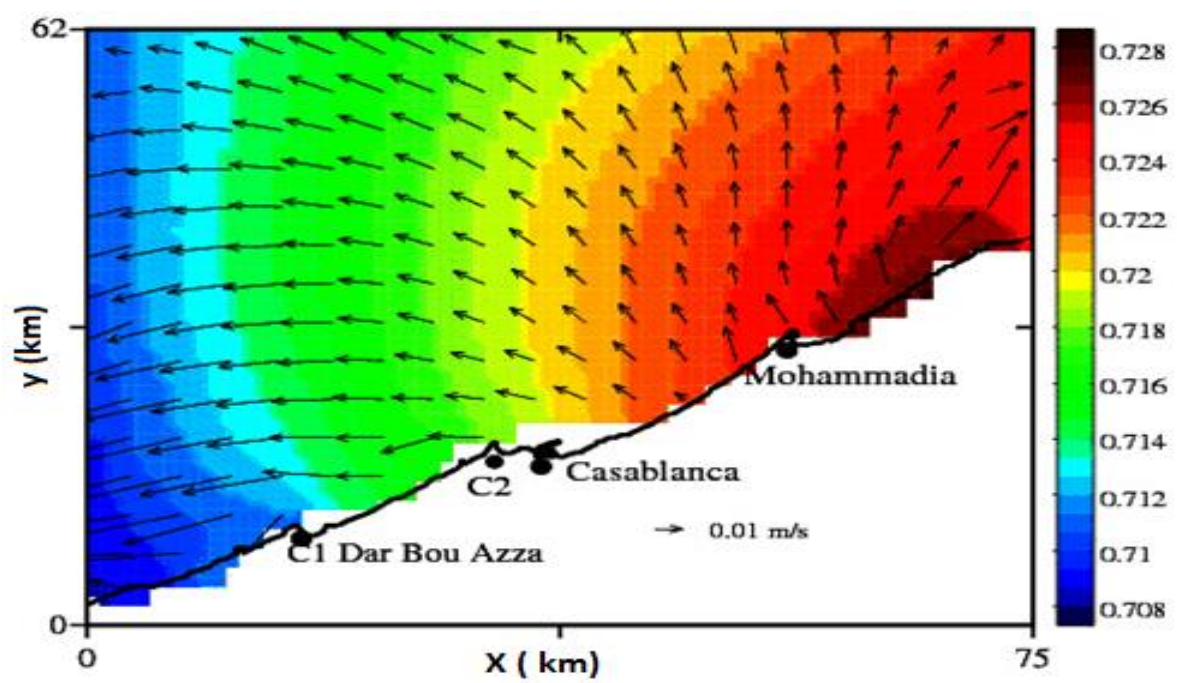

Fig. 3: Sea Surface Elevation (M) and Current Field at Low Water. 


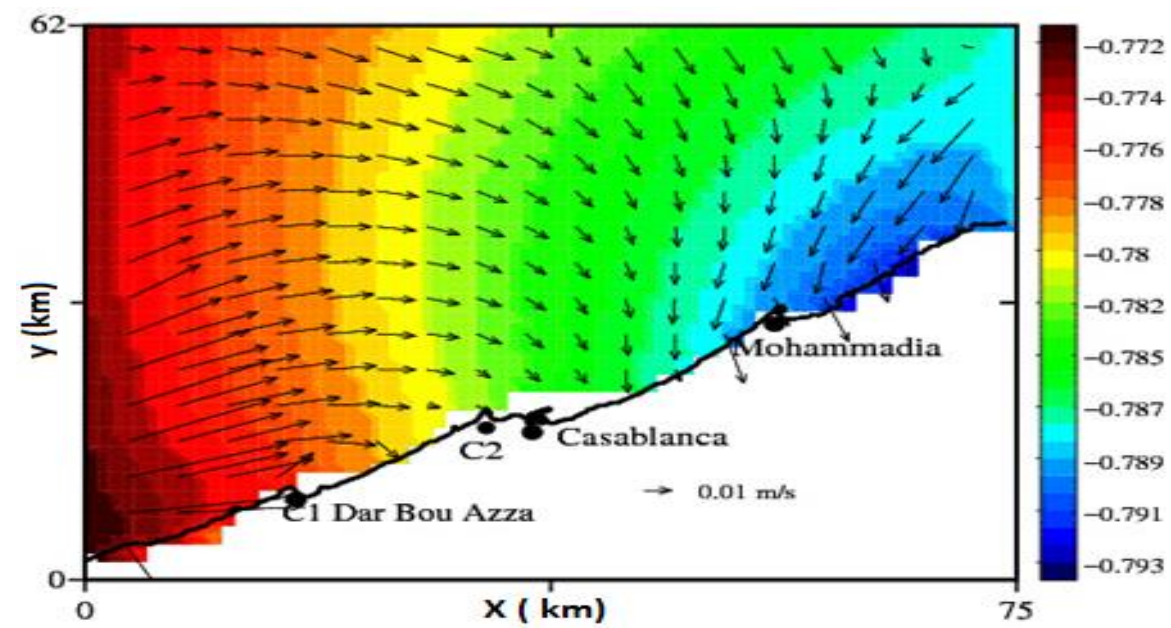

Fig. 4: Sea Surface Elevation (M) and Current Field at the High Water.

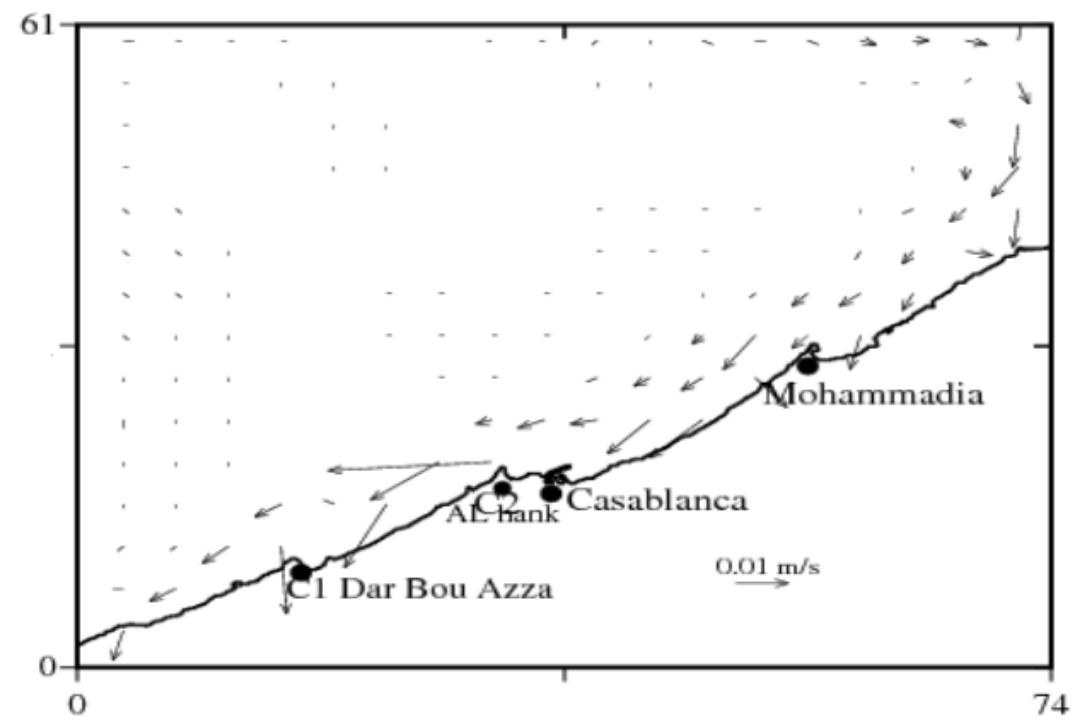

Fig. 5: Residual Current of the M2 Tidal Wave.

\section{Conclusion}

This modelling study constitutes, to our knowledge, the first study regarding the tidal influence on the Coastal area of the Casablanca-Mohammedia. We studied the contribution of the forcing tidal on coastal hydrodynamics; modeling conducted in this paper was based on 2D version of the MECCA model. These preliminary results show that the model is able to reproduce major features of the tidal flow in this region. It is clearly noted that this attempt of the numerical modelling of the flow in the coastal areaCasablancaMohammedia can not substitute a global modeling of the water circulation in this area (a 3D modelling is necessary).

The courantologique study in the area of Casablanca Mohammedia showed that the currents are mainly tidal currents, with the predominance of the M2 semi-diurnal component.

The comparison of the results of the MECCA numerical model and the TPXO altimetry model allowed a first analysis of the quality of the simulations and a first validation of the model on the study area.

The objective of this study is reached, since its principal aim is the understanding of tidal flow in the coastal area of the CasablancaMohammedia. It is evident that a $2 \mathrm{D}$ modelling is not able to reproduce all others circulation aspects. In the future, we tempt to use a 3D version of MECCA model to simulate others major features of the flow in the Casablanca-Mohammedia area.

\section{References}

[1] Munk W.H. and E.P. Anderson (1948): Note on the theory of thethermocline. Journal of Marine Research 7.pp 276-295.

[2] Blackadar A.K. (1962): The vertical distribution of wind and turbulentexchange in a neutral atmosphere Journal of Geophysical Research67, pp3095-3120.https://doi.org/10.1029/JZ067i008p03095.

[3] Smagorinsky J (1963): General circulation experiments with the primitive equations, Part 1: The basis experiments. Monthly Weather Review. 91, pp 99-164. https://doi.org/10.1175/15200493(1963)091<0099:GCEWTP>2.3.CO;2.

[4] Hess K.W (1986): Numerical model of circulation in Chesapeake Bayand the coninental shelf .N.O.A.A.Technical Memorandum, US. Departement of Commerce, (Report).

[5] Bills P. and J. Noye (1987): An investigation of open boundary conditionsfor tidal models of shallow seas. in J. Noye (Eds) $\mathrm{Nu}$ merical modelling: Applications to Marine systems,ElsevierSci, New York,pp 159-194, (Edited Book).https://doi.org/10.1016/S0304-0208(08)70034-3.

[6] Blumberg A.F. and G.L. Mellor, (1987): A description of a three dimensional coastal ocean circulation model, in N.S. Heaps (Eds) Three-Dimensional oastal Ocean Models, Coastal and Esturine Sciences, 4 A.G.U.,Wachington (D.C.), pp 1-16, (Edited Book). https://doi.org/10.1029/CO004p0001.

[7] Smaoui.H (1996) : Modélisation numérique tridimensionnelle de l'hydrodynamique et des transports sédimentaires en Manche Orientale et dans le sud de la Mer du Nord. Thèse Doct. Maths. Appli., Université de Lille1, France, pp 310, (PhDthesis).

[8] Hess, K, W (2000), MECCA2 program documentation US. Dept of Commerce National Oceanic and Atmospheric Administration, Na- 
tional Ocean Service Office of Coast Survey,Coast Survey Development Laboratory.

[9] Cherniawsky, J., M. G. G. Foreman, W. R. Crawford, and R.Henry,(2001): Ocean, Tides fromeTopex/Poesidon sea level data. J. Atmos. Oceanic Tech., 18, 649-664. https://doi.org/10.1175/1520-

0426(2001)018<0649:OTFTPS $>2.0$. CO;2.

[10] Smaoui, H., Ouahsine, A. (2006). 2D numerical simulation of the tidal flow in the Strait of Gibraltar. Report of the Convention CNRS/CNRST, Contract SP105/06 